CASE STUDY

\title{
Serving the Adult Student \\ at University of \\ Maryland University \\ College
}

June 9, 2016

J essie Brown

Deanna Marcum

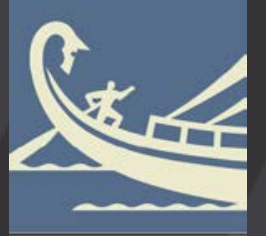

ITHAKA S+R 


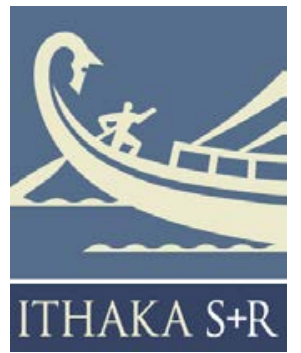

Ithaka $\mathrm{S}+\mathrm{R}$ is a strategic consulting and research service provided by ITHAKA, a not-for-profit organization dedicated to helping the academic community use digital technologies to preserve the scholarly record and to advance research and teaching in sustainable ways. Ithaka $\mathrm{S}+\mathrm{R}$ focuses on the transformation of scholarship and teaching in an online environment, with the goal of identifying the critical issues facing our community and acting as a catalyst for change. J STOR, a research and learning platform, and Portico, a digital preservation service, are also part of ITHAKA.

Copyright 2016 ITHAKA. This work is licensed under a Creative Commons Attribution-NonCommercial 4.0 International License. To view a copy of the license, please see http://creativecommons.org/licenses/by-nc/4.0/.

ITHAKA is interested in disseminating this brief as widely as possible. Please contact us with any questions about using the report: research@ithaka.org. 


\section{Introduction}

Conventional conceptualizations of the "typical" college student as an eighteen-year old, full-time, residential student poorly match reality. Roughly 70 percent of today's college students are "nontraditional students," meaning that they are over the age of 24 , commute to campus, work part or full-time, are financially independent, or have children. Some enter college with only a GED, while others are reentry students with an assemblage of credits from various institutions. Many of these students are low-income, the first in their families to attend college, or come from underrepresented racial and ethnic groups. ${ }^{1}$

\section{The educational delivery formats and financial aid policies of many four-year colleges and universities are not well- designed to support these nontraditional students.}

The educational delivery formats and financial aid policies of many four-year colleges and universities are not well-designed to support these nontraditional students. Most institutions require that students rearrange their schedules and sideline competing life demands so that they can participate in a system designed for students who have recently completed high school. This can be an unreasonable demand for students who must work full-time, commute long distances, or have families to support, and leads many to withdraw from post-secondary institutions all together.

This case study looks at The University of Maryland University College (UMUC), an institution that was planned-from inception - to serve geographically dispersed adult learners and makes supporting these types of student central to all of its operations. This report traces UMUC's development from a division within University of Maryland, College Park, designed to serve veterans and military students, to its establishment as an independent, non-profit, public institution within the University System of Maryland (USM). In particular, we focus on recent curricular and operational changes at UMUC and illustrate how, in recent years, UMUC has enhanced its mission to equip adult

\footnotetext{
${ }^{1}$ See Jessie Brown, "Shifting Policy to Support the 'Typical' College Student," Ithaka S+R Blog (August 14, 2015), http://www.sr.ithaka.org/blog/shifting-policy-to-support-the-typical-college-student/; Jenna Johnson, "Today's Typical College Students Often Juggle Work, Children and Bills with coursework," The Washington Post (September 14, 2013), https://www.washingtonpost.com/local/education/todays-typical-college-students-often-juggle-work-children-and-bills-withcoursework/2013/09/14/4158c8c0-1718-11e3-804b-d3a1a3a18f2c story.html
} 
learners with twenty first-century skills through effective leadership, the diligent use of data, and a culture of collaboration.

Currently, UMUC serves nearly 85,000 students (nearly 70,000 undergraduates). It is headquartered in Adelphi, Maryland, and offers classes and services at several locations throughout the state and the country. UMUC also offers face-to-face courses at military bases in Europe, Asia, Africa, and the Middle East, but most students take their courses online. ${ }^{2}$ The university is notable among public four-year institutions for its strong focus on online course delivery, the emphasis it places on workforce development, its faculty model, and its use of data for student support, program design, and institutional decision making. The institution uses each of these approaches to deliver on its mission to support adult students.

To get a better sense of how its singular focus on serving the needs of nontraditional, adult students structures its operations, we spent two days at UMUC in February 2016 interviewing administrators, staff, and faculty. In addition, we spoke via phone with students who were enrolled in UMUC's online courses. In our interviews, we focused on UMUC's approach to adult learning, paying special attention to recent changes and initiatives, many of which are still in progress.

While UMUC's history of serving adult students makes it distinctive, the strategies it has pursued to support this population provide valuable lessons to a variety of institutions that enroll growing shares of nontraditional learners. In addition, UMUC's organizational culture and successful approach to change management have allowed the institution to be remarkably effective in advancing substantial, mission-aligned innovations over the past several years. While some of the factors that have allowed UMUC to successfully transform are unique to the institution, others are more broadly applicable, and offer rich examples of strategic change management in higher education.

\section{Origins and Operations}

From its creation, UMUC has been at the forefront of adult education and distance education, especially for military students. The institution began as a unit within University of Maryland College Park's College of Education, called the College of Special and Continuation Studies (CSCS). Established in 1947, the unit was designed to accommodate the increasing enrollment of veterans after World War II and the passage

\footnotetext{
${ }^{2}$ In 2015, 86 percent of all enrolled students took at least one course online. See UMUC's Fiscal Year 2015 Fact Book, Prepared by the Office of Institutional Research (2015), http://www.umuc.edu/visitors/about/ipra/upload/umuc-fact-bookfy15.pdf.
} 
of the GI Bill. CSCS was re-named University College in 1959, offering educational options to civilians and their families in Maryland, Asia, Europe, the North Atlantic, Africa and the Middle East. In 1970, it became a separately incorporated and accredited institution-University of Maryland University College - within the University System of Maryland. Throughout the course of these developments, the institution maintained its focus on serving adult and military students. ${ }^{3}$

Today, UMUC continues to operate physical locations on military bases in more than 20 countries in Asia and Europe. However, since the 1990s, due to the combination of a shrinking military and increasing interest in and capacity for online education, UMUC began to focus more on stateside operations and digital education, while maintaining its focus on educating adult, nontraditional, and military students. In fiscal year 2015, UMUC enrolled almost 52,000 active duty military, reservist, dependent, or veteran students. Approximately 75 percent of stateside enrollees worked full-time, 54 percent were working parents, and the median age for stateside undergraduates was $31 .{ }^{4}$

\section{Despite some of the apparent and real similarities between UMUC's educational model and those of for-profit institutions, UMUC's fees are substantially less than those charged at most for-profit institutions, and its investment strategy focuses on providing value to students, rather than profit for the institution.}

Despite this distinct focus, UMUC remains one of the 12 non-profit, public institutions within the University of Maryland system, and 32,000 of the nearly 85,000 students it serves reside within the state of Maryland (though most take courses online). UMUC receives fewer allocations from the state than any other institution within the system, but still retains a public mission to offer its students a quality, affordable education (currently, it has the second lowest tuition of all USM schools). Therefore, despite some of the apparent and real similarities between UMUC's educational model and those of for-profit institutions, UMUC's fees are substantially less than those charged at most for-

\footnotetext{
${ }^{3}$ For UMUC's history, see "Strategic Plan 2015-2018," University of Maryland University College (2015), https://issuu.com/umucachiever/docs/umuc strategic plan?e=5712148/12994035.
}

4 "UMUC at a Glance," UMUC Office of Institutional Research," http://www.umuc.edu/visitors/about/ipra/. 
profit institutions, and its investment strategy focuses on providing value to students, rather than profit for the institution. In addition, because of its long-standing commitment to serving adult and nontraditional students, UMUC sits at the forefront of system efforts to instill a culture of innovation and promote workforce development. USM leaders hold up UMUC's innovative initiatives as examples of what more traditional institutions in the system should aspire to achieve.

\section{The Student Experience}

When asked to describe UMUC's approach to education, Marie Cini, provost and senior vice president of academic affairs, explains that every decision at UMUC is informed by serving the adult student. "When you focus on the student," explains Cini, "everything else comes naturally." Our interviews with other UMUC staff, faculty, and administrators, as well as the additional research we have done on the institution, corroborate the primacy of the learner.

\section{The flexibility of online courses works especially well for students with family, professional or other life obligations, and can be effective at increasing access for nontraditional students while removing logistical barriers to completion.}

One of the most apparent-and increasingly mainstream - ways in which UMUC's approach accommodates the adult learner is through online course delivery. UMUC was an early pioneer in online education and has been offering online courses since 1993 (before this, UMUC offered correspondence distance options to overseas students). Today, UMUC online course delivery constitutes a substantial share of the institution's operations: in fall 2015, UMUC offered 927 unique online courses (4,736 sections) and 87 percent of all enrolled students took at least one online course. ${ }^{5}$ As leaders and faculty at many other institutions are coming to realize, the flexibility of online courses works especially well for students with family, professional or other life obligations, and can be effective at increasing access for nontraditional students while removing logistical barriers to completion.

\footnotetext{
5 "UMUC Fall 2015 Factbook," UMUC Office of Institutional Research (Fall 2015), http://www.umuc.edu/visitors/about/ipra/upload/umuc-factbook-fall-2015.pdf.
} 
UMUC's approach to online education is noteworthy not only for its scale and history, but also for the thought and effort invested in creating remote communities of students and faculty. Students with whom we spoke reported that online discussions and forums were often more engaging and participatory than face-to-face courses they had encountered in earlier educational experiences. Faculty have regular remote meetings, as well as ad-hoc video and conference calls to troubleshoot larger curricular issues, and program chairs are intentional about creating faculty communities of practice. Faculty members also use a social media platform that creates communities by class through which they share resources and discuss strategies for a given course.

Nearly all of UMUC's courses are taught by adjunct faculty members who work part-time and are hired on a contract basis. All adjunct faculty are what UMUC calls "scholarpractitioners," meaning that they have advanced degrees and actively work in the field in which they teach. Institutional leaders explain that this model, which has been in place since the institution was established, stems directly from UMUC's focus on the adult learner: giving students the opportunity to learn from professionals in their field adds richness to UMUC's curricular focus on workforce development. Faculty are hired as professional teachers, not as discipline-based research faculty, thereby strengthening the student-centric approach.

While UMUC's heavy reliance on adjuncts may raise eyebrows among traditional tenuretrack faculty, especially with the increasing use of contingent faculty at traditional institutions of higher education, it is an intentional part of UMUC's pedagogical and educational model, rather than an explicit cost-saving strategy at odds with educational quality. Students with whom we spoke reported that they enjoyed learning from people in their intended (or current) professional field, and faculty explained that their students benefitted from hearing about their practical experience and insights. Institutional leaders are clear about their expectations for faculty to teach, and are decisive in their understanding that the role is for professionals interested in giving back, rather than for scholars invested in disciplinary research. The institution's hiring practices and recruitment communications are explicit about this.

UMUC's student-centric, workforce-oriented faculty model has also allowed the institution to make broad sweeping changes more quickly than more traditionally structured schools can, while allowing it to scale educational operations to 84,000 students. Like many of UMUC's other operations, this approach grows out of the institution's focus on what works best for adult learners, and has allowed the institution to provide broader access and more appropriate educational experiences for these learners. 
In addition to offering online courses taught by scholar-practitioners, over the past several years, UMUC has built up a strong, centralized support system for online students. Particularly notable is what UMUC calls its first-tier support system, which is a 24-hour call center from which students can seek advice on issues related to registration, financial aid, technical issues, and campus resources. If a student needs additional support, he or she is referred to an advisor or staff member with more specialization. This system, which borrows many of its approaches from the corporate customer service world, works well for digitally engaged and globally dispersed students, and ensures that busy students can easily resolve financial aid, registration, technical, or similar issues with a single telephone call at whatever time they need assistance.

\section{Recent Changes in Leadership and Culture}

These recent changes in UMUC's student support strategy are indicative of a larger shift at UMUC. While UMUC has always focused on serving adult learners, it has done so especially effectively through a series of recent functional changes and curricular innovations. These transformations were catalyzed by turnover in senior leadership, and accelerated by mounting pressure to increase enrollments, manage resources, improve student outcomes, and better bridge the career skill gap. Strong leadership successfully implemented a process of change based on an institutional investment in data and analytics, and an intentionally collaborative approach to planning and design.

There is a broad consensus across campus that the initiatives and strategies that we discuss in this section would not be possible without the leadership of President J avier Miyares and Provost Marie Cini. Miyares, previously the senior vice president for institutional effectiveness, stepped in as interim president in 2012, and, after demonstrated success, continued in the role. By his own admission, Miyares never imagined himself as a university president. Rather, he considered himself the "data-guy," and many of the changes under his leadership have been informed, designed, and refined under the guidance of the newly created UMUC Office of Analytics. ${ }^{6}$

Spearheaded by Miyares, the office of analytics employs a highly-skilled team of analysts who not only have backgrounds in data analysis, but also have experience in various functional areas of the institution. Analysts work as embedded team members or consultants within the functional areas in which they have expertise, helping these teams better understand their data and make decisions informed by their analyses. This collaborative analytical approach has been used to improve processes and outcomes in a

\footnotetext{
${ }^{6}$ See Meris Stansbury, "College president reimagines analytics with dramatic success," eCampus News (November 2 , 2015), http:// www.ecampusnews.com/top-news/ office-of-analytics-265/
} 
variety of areas, from enrollment management, to marketing, to finance, to student retention and success. Faculty and staff speak favorably about the marked shift in institutional culture that it has affected. ${ }^{7}$

Shortly after stepping into the role of president, Miyares appointed Marie Cini as interim provost in J une 2012, and then permanently as provost and senior vice president of academic affairs in 2013. Previously, Cini was the vice president and dean for UMUC's undergraduate school. She held similar roles in other institutions before coming to UMUC, but her entire career had been focused on working with adult students. With this background, Cini entered the role of provost with an orientation towards innovation and risk-taking. She speaks with conviction about the importance of nontraditional thinking and nontraditional approaches at UMUC.

\section{Crucial to UMUC's successful process of change management has been a strong, distributed leadership team that is open to new ways of working and collaboration.}

Cini's innovative vision has been behind many of UMUC's recent curricular innovations (discussed below), while Miyares' commitment to collaborative, data-driven decision making has provided a useful methodology through which these innovations have been designed and implemented. Also crucial to UMUC's successful process of change management has been a strong, distributed leadership team that is open to new ways of working and collaboration. In particular, Cini and Miyares have been strategic about assembling a staff of leaders with a diverse range of backgrounds in corporate settings, for profit-institutions, public non-profit education. Leaders with corporate backgrounds have implemented systems and approaches that are useful for efficiently managing so many dispersed students at a large scale (such as high-capacity, centralized business systems and the 24-hour student call-in center). Part of the motivation for hiring leaders from corporate and for-profit educational institutions is to ensure that UMUC can keep pace with other adult-serving institutions while remaining true to its public mission.

${ }^{7}$ In 2015, UMUC spun its office of analytics off as a profit-making venture called Heliocampus. UMUC will use its data analytics capacity, as well as its unique consulting model, to help other institutions make better use of their data. See the Heliocampus website, http://www.heliocampus.com/. See also Sarah Gantz, "UMUC turned its Office of Analytics into a software startup," Baltimore Business Journal (September 22, 2015),

http://www.bizjournals.com/baltimore/blog/cyberbizblog/2015/09/umuc-turned-its-office-of-analytics-into-a.html. 


\section{Transforming the Academic Model}

The UMUC leadership team has adopted some significant curricular and structural changes, and is in the process of dramatically redesigning its learning model around program-based competencies. This work started several years ago when Cini took the role as provost, restructured academic affairs, and focused the curriculum around adult learners in an increasingly integrated way. In UMUC's new organizational plan, directly underneath the provost are two deans: one for the graduate school and one for the undergraduate school. Deans oversee program chairs in each academic program, who lead in the hiring and training faculty, manage curriculum development in their program, act as liaisons between faculty and deans, and handle other administrative duties. Program chairs have collegiate faculty standing, work on rolling contracts, and have a small teaching load coupled with administrative responsibilities. They work fulltime and have advanced degrees, but most also have extensive professional experience in their program field.

One of the main motivators for the restructuring of academic affairs was an accompanying effort to create a consistent and integrated learning experience at UMUC, which previously varied across sections and continents. UMUC's curriculum is now designed by a team of programs chairs and collegiate faculty, in partnership with instructional designers, and informed by relevant industry stakeholders, and a profession-based advisory board. Adjuncts with expertise are often brought into this process, but most teaching faculty do not participate in curriculum design. Instead, all adjuncts that teach a given course are given a framework for teaching with embedded course materials. Adjuncts have some room for customization within this framework, but, for the most part, are required to use uniform materials, learning outcomes, and assessments. ${ }^{8}$

The shift to a more standardized curriculum development process began in the 2000s, and has evolved to today's centralized model. There were several reasons for this shift: first, UMUC has made concerted efforts over the past several years to make its operations more uniform across international locations. Along with centralizing the curriculum, UMUC has adopted uniform learning management and student management systems across the institution. Second, because of UMUC's unique faculty model, in which 90 percent of faculty work part-time and on a contract basis, ensuring that faculty can focus solely on course delivery and student support is crucial.

\footnotetext{
${ }^{8}$ One law enforcement adjunct faculty member with whom we spoke said that weaving his own experiences, insights, and antidotes from 25 years as a police officer was a valuable strategy to enhance student learning and engagement.
} 


\section{Learning outcomes are designed at the program level and courses and assignments are reverse engineered from these standards.}

Most importantly, centralized curriculum development has served as a vehicle through which UMUC can organize its curriculum. In this new model, learning outcomes are designed at the program level and courses and assignments are reverse engineered from these standards. This approach has served as a basis from which UMUC has been able to offer students more streamlined paths to graduation and employment, while setting the foundation for UMUC's current efforts to design its new academic model, called the Enhancing Learning Model, or ELM, around a competency framework. ${ }^{9}$

Cini and Miyares have led two other initiatives that have set the foundation for ELM. First, acknowledging, like many at broad-access institutions have in recent years, that the "cafeteria" model of varied course offerings works against student progression and career alignment, UMUC launched the "Straightline Path Initiative" in 2012. The dean of the undergraduate school engaged program chairs and collegiate faculty to think about the goals of and optimal pathways through their programs. With these "roadmaps," UMUC reduced its 1,100 courses to 700 courses and now offers more directed advising to undergraduate students depending on their goals. Course reduction has also allowed for course development efforts to be more focused, and has increased the effectiveness of course quality assurance.

Second, starting 2013 and finishing in 2016, the university replaced all physical textbooks with bundles of open e-resources and digital library resources. The primary driver for this change was increased access savings to students: to date, UMUC has saved students, collectively, about \$17 million, and it is much easier to ensure that UMUC's globally dispersed student body has access to the resources they need from the first day of the term. However, the process of identifying the best open educational resources for the courses also engaged faculty and administrators in thinking, at the program level, about programmatic outcomes that would best meet these standards. Like curriculum centralization and Straightline Path, this solidified UMUC's programmatic curricular focus, and established collaborative processes for future work.

\footnotetext{
${ }^{9}$ See "Undergraduate Learning Model," University of Maryland University College, https://www.umuc.edu/facultydevelopment/upload/LearningModel.pdf.
} 
ELM, UMUC's latest curricular initiative to adopt a competency framework, builds on each of these changes. Under this model, UMUC will implement rigorous key competencies for each academic program and establish mastery-based learning activities and assessments matched to those competencies (rather than retrofit learning outcomes to assignments, learning activities are "reverse engineered" from competencies). The adjunct faculty will continue to play a key role in the new learning model, facilitating learning and mentoring students to achieve high levels of mastery. Competencies, which are designed with significant input from industry partners, match closely to what students are expected to know and do in their chosen professional field, and learning activities engage students in workplace problem solving much more directly than traditional final papers or exams. To avoid too vocational of an approach, UMUC leaders and faculty will be careful to build skills like critical thinking into the curriculum and competencies, and are dedicated to thinking not only about what graduates will need to know, but also how they will have to think, in order to be successful in their careers and lives.

\section{UMUC is also redesigning its transcript to better represent student accomplishments by competencies, rather than through abstracted course grades.}

UMUC is also redesigning its transcript to better represent student accomplishments by competencies, rather than through abstracted course grades. ${ }^{10}$ While financial aid and GI Bill regulations will keep UMUC constrained to the credit-hour and semester system for the foreseeable future, leaders are experimenting with ways to incorporate a more flexibly-paced, mastery-based approach within the time constraints of the semester. In courses piloted in fall 2015, nearly all students who earned an "incomplete" because they did not master concepts within the allotted time of the semester ended up completing the course successfully during the following term.

This competency framework reinforces UMUC's mission to serve adult and nontraditional students. ELM will better meet students where they are, so that students who have mastered competencies through prior professional and educational experiences need not spend time or credit hours on remedial materials, while those with

\footnotetext{
${ }^{10}$ This work is part of the Comprehensive Student Record project led by the American Association of Collegiate Registrars and Administrative Officers. See "Daniel Leaderman, "UMUC to test extended transcripts with more data," The Daily Record, http://thedailyrecord.com/2016/02/29/umuc-to-test-extended-transcripts-with-more-data/.
} 
gaps in their knowledge and skillset can spend the appropriate amount of time filling them. This accounts for the broad range of experiences with which students enter the institution, and within certain constraints, allows students to master concepts at their own pace and on their own schedule. ${ }^{11}$ Additionally, ELM's alignment between curricular and employer expectations fits well with the goals of UMUC students, who by and large come to UMUC to expand their career opportunities.

Though UMUC piloted ELM in four cyber security courses last fall, the program is still very much in development. As Cini, Miyares, and deans have led this process, they have been diligent about making it collaborative and evidence based. Stakeholders from across the institution report that they feel that they not only "have a seat at the table," but are expected to contribute, ask questions, and be familiar with communications and resources about the project. Because this curricular transformation will impact nearly all other operations, leaders from other functional areas, like advising and analytics, have been brought into the design process as collaborators since inception. Program chairs, deans, and administrators have set up feedback pathways and focus groups for students and faculty in piloted courses, and, going forward, the Office of Faculty Development will be heavily engaged in training faculty for the shift in roles that ELM will necessitate. Throughout all of this, UMUC's strong business intelligence systems and Project Management Office, which bring lessons from the business world to UMUC's approach to change management, have ensured that the project is on track to reach well-defined milestones.

\section{Evidence of Impact}

By enrollment numbers, UMUC's mission to serve adult and nontraditional learners is evident: as of spring 2014, UMUC enrolled nearly 83,000 students, 37 percent of whom were first generation college students. Forty eight percent have children residing in the household, 14 percent were born outside of the US, and 10 percent speak a first language other than English. ${ }^{12}$ UMUC remains the second most affordable institution in the USM system. It ensures that students who transfer from a Maryland community college to UMUC can complete their entire degree (community college credits included) for no

\footnotetext{
${ }^{11}$ As dramatic as UMUC's move to a competency-based curriculum is, the institution will likely have to find ways to incorporate a self-paced approach to learning into a traditional credit-hour and semester model to meet financial aid and GI Bill regulations. UMUC is designing other ways to accommodate students who work at different paces, and, in its cyber security pilot courses in fall 2015 , nearly all students who earned an "incomplete" because they did not master concepts within the allotted time of the semester ended up completing the course.

12 "UMUC at a Glance," UMUC Office of Institutional Research, http://www.umuc.edu/visitors/about/ipra/glance.cfm.
} 
more than $\$ 20,000$, and is piloting a "promise" program that will offer high school students who participate in dual enrollment programs and go to a local community college the opportunity to complete their degree at UMUC for less than $\$ 8,000$ in tuition and fees (average net price for all students receiving some form of aid was just over $\$ 10,500$ in 2013-2014). ${ }^{13}$

Like most broad access institutions, UMUC's conventionally calculated graduation rate lags behind those of more selective schools. The conventional graduation rate does not parse out the many students at UMUC who are lifelong learners or other students who many not have ever intended to earn a degree, or those students who earn some credits at UMUC and finish elsewhere. Despite these caveats, UMUC's six-year graduation rate has increased in recent years. For the 2006 cohort, 18 percent of first bachelor's degree seeking undergraduates graduated within six years, and an additional 10 percent had reenrolled. For the 2009 cohort, 24 percent graduated within six years, and an additional eight percent were still enrolled. These leading indicators are promising for increasing graduation rates in 2017 and beyond.

UMUC's other interim measures of success have also increased over time. The course completion rate in UMUC's undergraduate programs increased from 67 percent in fall of 2010 to 77 percent in fall 2015. Over this same time period, fall to spring re-enrollments for undergraduates increased from 76 percent for fall 2010 to spring 2011 to 79 percent for fall 2015 to spring 2016. With 84,000 students, this means that thousands more students are progressing successfully through their programs. ${ }^{14}$

UMUC's new approach to data analysis and problem-solving has yielded measurable results on a smaller, yet no less effective, scale. For example, when an analysis showed that students who registered for class late had a much higher chance of failing or not completing, UMUC implemented a new drop/ add timeframe during which students could drop courses without financial penalty. The policy also made it so that students could not add a course less than four days before a class began. One year after the policy was implemented, institution-wide course completion had increased by five percentage points, while the share of students who earned C's or better in their courses increased by three percentage points. ${ }^{15}$

\footnotetext{
${ }^{13}$ Data from IPEDS.

${ }^{14}$ Information provided by Marie Cini.

${ }^{15}$ See Elizabeth Mulherrin, "Personalization at Scale: Using Analytics for Institutional Improvement," The Evollution: $A$ Destiny Solutions Illumination (February 23, 2016), http:/levolllution.com/attractingstudents/customer service/personalization-at-scale-using-analytics-for-institutional-improvement/.
} 
As is evident from recent changes to its curricular model, UMUC places a strong emphasis on workplace development. Students report that UMUC is effective in this area. On a survey of students who received their bachelor's degrees in 2013, 63 percent selected "excellent" or "good" when asked how well UMUC prepared them for their current job. In response to a similar question about preparation for graduate or professional study, 85 percent selected excellent or good. Seventy-eight percent responded that they were currently employed, and median reported salary was $\$ 59,166 .{ }^{16}$ Student interviews substantiate this point: students feel engaged, understand how their coursework relates to their professional goals, and appreciate the opportunity to work with professionals in their fields.

\section{Success Factors}

As discussed, UMUC's success in serving adult students and managing change is the product of several factors. Here, we highlight and summarize these success factors, most of which are more broadly applicable to other institutions innovating for student success.

\section{A Clear and Well-Established Commitment to Serving Adult Learners}

From our first interview with President Miyares and his administrative team to the last with faculty and staff, we heard an unwavering message: UMUC is totally focused on the adult student. Since the College was created in 1947, it has focused on adult learners both in the United States and abroad on military bases. Today, this focus permeates all of UMUC's operations, from its scholar-practitioner faculty structure, to its focus on online education, to its student support system, and its continuous curricular improvements. UMUC's hiring strategy also reflects this approach, and the institution has been intentional about assembling a team of leaders with backgrounds in diverse educational contexts who can develop innovative approaches to supporting adult learners. This singular institutional focus on the adult learner removes ambiguity from institutional decision making processes and creates room for experimentation and innovation.

\section{Strong Executive Leaders with a Clear Vision for Change}

Miyares' and Cini's leadership has been instrumental in fortifying UMUC's mission to serve the adult student. Cini's commitment to finding innovative approaches to helping adult learners succeed, combined with Miyares' dedication to leading with data, have affected a culture shift at UMUC while driving forward exciting changes in the school's

\footnotetext{
${ }^{16}$ See "The UMUC Student Profile," UMUC Office of Institutional Research (Fall 2015), http://www.umuc.edu/visitors/about/ipra/upload/student-profile-and-graduation-rates.pdf.
} 
academic model and decision-making processes. In addition, both Miyares and Cini have been consistent in their messaging about UMUC's mission, the importance of nontraditional approaches, and the value of data. Faculty and staff have great trust in Cini's and Miyares' approach, and express appreciation for the clarity and consistency of administrative direction.

\section{Passionate Distributed Leadership}

Distributed leadership is another hallmark of the administration of UMUC. Cini and Miayres have been strategic about recruiting leaders who can bring in new perspectives from outside of the organization, while also leveraging internal employees those whose passion and energy for innovation were high. In the former category of hires is Kara Van Dam, who had been the vice president for academic affairs at Kaplan. As vice provost for the learner and faculty experience, Van Dam oversees the introduction and approval of new programs, competency-based educational programs, and faculty development. Similarly, Brian Gnatt, assistant vice president for customer experience, was hired from the commercial sector and has started up the customer experience discipline in order to identify and implement critical improvements to the UMUC student experience working across all student-facing teams at the University. From within the organization, Matt Prineas, who has had a long career at UMUC, was appointed vice provost and dean of the undergraduate school after leading high quality innovations within the undergraduate school.

In addition, Aric Krause, vice provost for the graduate school and Karen Vignare, vice provost, center for innovation in learning and student success have been crucial hires for UMUC's leadership team. Both Krause and Vignare have strong experience in traditional academic environments, but were drawn to the needs of adult learners and had an affinity for the work at UMUC. They have assembled a team of creative individuals who are committed to using learning sciences to transform education for adult learners, and have been instrumental in the process to redesign UMUC's academic model.

\section{A Collaborative Approach to Data-Driven Decision Making}

UMUC has been particularly effective at using data to drive institutional decision making; so much so that, in 2015, it spun out its office of analytics into a separate analytics service. As discussed, President Miyares, who previously been senior vice president for institutional effectiveness, was instrumental in orienting UMUC's culture around analytics. As president, he spearheaded the creation of the office of analytics, and has built a strong team with backgrounds in advanced analytics-mostly in the corporate world-to grow UMUC's capacity. 
UMUC is notable not only for its analytics capacity, but also for the unique approach it has taken to making data-driven problem solving a robust part of UMUC's culture. Analysts from the office of analytics work closely with representatives from the institution's functional areas to help them understand their data and to inform their decision-making. This approach, which allows for stakeholders to make sense of quantitative information in light of their own experiences and functional strategies, has been crucial for both the formation of a culture that embraces the use of data, as well as for the optimal design of new initiatives and strategies.

\section{Collaborative, Well Managed Project Planning}

In our interviews, we consistently heard that the process for designing and planning ELM was genuinely collaborative. Representatives from academic affairs, student support, and the office of analytics all reported that they were expected to contribute meaningfully, and to take responsibility for thinking through how the transformation of the academic model would impact their area of the institution. In addition, stakeholders reported there was a clear line of communication between them and institutional leaders: they felt welcome to ask questions, well-informed on the logic behind the academic transformation, and encouraged to give feedback throughout the planning process. Despite the dramatic scope of the project and the multiplicity of stakeholders involved, UMUC has leveraged its office of project management to keep the process on track, and leverages resilient, cost-effective, and scalable computing resources (supported by a recent migration to the cloud) to manage multiple project pieces and support the continuously changing needs of the institution.

\section{Unique Faculty Structure}

UMUC's unique faculty structure - in which nearly all instructors work part-time, on a contract-basis, and are established professionals in their fields-works particularly well for the institution's centralized curricular model, and makes large scale initiatives easier to move forward. Students also report that they benefit from learning from someone with experience in their chosen field, especially because many UMUC students already work full or part time.

UMUC's unique faculty model also ensures that the institution maintains its studentcentric focus. Faculty members' engagement with the institution is almost entirely teaching-oriented; they are not under pressure to produce disciplinary research, and they are assessed solely on their capacities as educators. While UMUC is currently strengthening its communities of practice for adjunct faculty to provide greater avenues for input and engagement, the lack of tenure has contributed to an environment in which innovative approaches are relatively easy to pilot, and where change can proceed at a 
faster clip than at more traditional schools. Certainly, UMUC's faculty model would not be appropriate at many institutions, but its commitment to aligning its hiring practices and organizational structure to promote student success should provoke inquiry into ways in which other institutions can better align faculty incentives within more traditional institutional models.

\section{Remaining Challenges}

While promising, UMUC's growing portfolio of projects also presents challenges for the institution, and it would be premature to say that the institution has completed thejob of managing transitions and change. In addition, the institution continues to face many of the challenges that prompted some of these large-scale changes in the first place, and is currently in the process of rethinking its business model in order to create more revenue streams.

Though work on ELM is underway, the project is still very much in progress. ELM's eventual implementation in academic programs will necessitate a significant rethinking of curriculum on the part of the adjunct faculty who deliver it and the students who receive it. In addition, while ELM has already been piloted in cyber security courses, scaling the competency framework to disciplines less explicitly focused on workforce preparation-such as the humanities and social sciences--may prove more challenging. Vice provost Kara Van Dam is already working closely with program chairs and collegiate faculty in these programs to determine how they can design meaningful learning activities for the new model. For example, students who major in history, who may go on to work in museum curation, work on projects that involve curating digital exhibitions.

In addition to ELM, UMUC is managing the roll out of several other initiatives, each of which will require time and resources. For example, student support services is in the process of developing a retention scoring and early alert system with Civitas. This process will necessitate additional training for advisors, and may raise new questions about ethics and privacy. Scaling the new, competency based transcript remains another on-going project, as do the programs regularly piloted by UMUC's center for innovation in learning and student success. ${ }^{17}$

More substantial are the financial and enrollment challenges that UMUC faces, which have forced leaders to rethink the institution's business model. Due to what Miyares has called a "perfect storm" of factors, UMUC has faced declining enrollment over the past

\footnotetext{
${ }^{17}$ See "Initiatives," UMUC's Center for Innovation in Learning and Student Success, http://www.umuc.edu/innovatelearning/initiatives/index.cfm.
} 
several years. Increasing restrictions and requirements on military education benefits, coupled with the global military drawdown, have decreased UMUC's presence abroad. In addition, competition from for-profit institutions for domestic and overseas students has left UMUC with a smaller share of the adult learner market. UMUC's recent move to a single global university, which was, in part, an effort to adjust to new constraints abroad and has meant the loss of jobs or job security for a number of overseas faculty, an adjustment that, not surprisingly, caused turmoil and friction. ${ }^{18}$

Dropping enrollment has necessitated that UMUC find ways to generate revenue without raising tuition. This is a challenging task for any institution, and is one that is compounded for UMUC because, in order to at least maintain enrollment, it must compete with for-profit institutions while maintaining its public mission. In 2014, in response to these mounting pressures, UMUC convened a task force of external experts that proposed that UMUC adopt a new business model. Under this new model UMUC would continue to be a non-profit entity within USM, but operate with more autonomy and enjoy exemptions from certain state rules governing procurement, human resources, and policies regarding protections for proprietary information. USM's trustees approved the proposal for this model in early 2015. While UMUC's new structure has allowed it more flexibility in operations, the institution continues to seek out strategies for increasing enrollment, and continually negotiates the challenges implicit in being an adult-serving institution within a public university system. ${ }^{19}$ Promisingly, UMUC's headcount has increased every year since 2012.

Finally, while UMUC's faculty structure has contributed to its student-centric focus, its recent centralization of the curriculum and continuing curricular changes have necessitated that it rethink roles and responsibilities. Currently, UMUC is in the process of implementing recommendations from an academic governance recommendations team, and is replacing its previous form of faculty governance with a new, more collaborative model that puts core faculty at the center of curriculum and academic matters.

\footnotetext{
${ }^{18}$ See Carl Straumsheim, "War on Multiple Fronts," Inside Higher Ed (September 8, 2014), https://www.insidehighered.com/news/2014/09/08/university-maryland-university-college-survival-war-multiple-fronts.

${ }^{19}$ Alissa Gulin, "UMUC gets go-ahead on concept for new business model," The Daily Record (January 29, 2015), http://thedailyrecord.com/2015/01/29/umuc-gets-go-ahead-on-concept-for-new-business-modell. See also "Ideation Study for UMUC: A Future Proposition, Executive Summary," UMUC Ideation Team (2014), http://www.umuc.edu/umucfuture/upload/ideation-study-for-umuc-executive-summary.pdf.
} 


\section{Conclusion}

Nearly everyone with whom we spoke on our visit opened their interviews by "warning" us that UMUC was not a traditional institution. Indeed, there are many things about UMUC that are nontraditional-from its singular focus on adult and nontraditional students, to its global and digital reach, to its centralized and increasingly competencybased curriculum. Yet, as the demographics of college students change, each of these aspects is becoming more and more common at institutions of higher education. In other words, while UMUC stands apart from many institutions in its demographic base and approach, increasingly, it is appearing innovative-but not entirely atypical.

\section{There are many things about UMUC that are} nontraditional-from its singular focus on adult and nontraditional students, to its global and digital reach, to its centralized and increasingly competency-based curriculum. Yet, as the demographics of college students change, each of these aspects is becoming more and more common at institutions of higher education.

Because UMUC was established to serve the adult learner, studying the infrastructure and processes it has set up to accomplish this mission should be instructive for a wide range of institutions that are accommodating more "nontraditional" student populations. Indeed, UMUC's use of online education, workforce-focused curricula, pathways approach, and adoption of open educational resources are all gaining traction in a variety of institutional contexts. Additionally, UMUC's approach to change management, which has leveraged strong and diverse leadership, a culture of data-driven decision making, and a collaborative planning and design processes hold valuable lessons for postsecondary schools involved in managing large-scale change. 


\section{Appendix}

We conducted the following interviews with faculty, staff, and administrators at University of Maryland University College on February 23 and 24, 2016. We conducted one phone interview with a student on March 25, 2016.

- Katrina Benjamin, Assistant Vice President, Student Recruitment Operations

- Marie Cini, Provost \& Senior Vice President, Academic Affairs

- Brian Gnatt, Assistant Vice President, Customer Experience

- $\quad$ Aric Krause, Vice Provost and Dean of Graduate School

- Lloyd “Milo” Miles, Senior Vice President, Global Military Operations

- David Mitchell, Adjunct Professor

- J avier Miyares, President

- J ack Neill, Sr. Director, Data Analysis

- Thomas Porch, Manager, Student Advising and Retention, Planning \& Initiatives

- Matthew Prineas, Vice Provost and Dean of Undergraduate School

- George Shoenberger, Senior Vice President \& Chief Business Officer

- J oellen Shendy, Associate Vice Provost \& Registrar

- Theo Stone, Manager, Employee Industry Relations

- Chris Tatem, Assistant Vice President, Solutions Design \& Development

- J eff Tjiputra, Program Chair, Computer Information Systems and Technology

- Kara Van Dam, Vice Provost, Learner \& Faculty Experience

- Karen Vignare, Vice Provost, Center for Innovation in Learning \& Student Success

- Pete Young, Senior Vice President, Analytics, Planning and Technology

- $\quad$ One current UMUC student 